\title{
Supporting Black, Indigenous, and Students of Color in Learning Environments Transformed by COVID-19
}

\author{
Min Mize \\ Winthrop University \\ U. S. A. \\ Crystal Glover \\ Winthrop University \\ U. S. A.
}

\begin{abstract}
This article sheds light on the challenges that Black, Indigenous, and students of color in the U.S. face in dealing with uncertainties and prejudice caused by the worldwide pandemic. It provides recommendations on culturally relevant, responsive, and sustaining teaching strategies based on the cultural competence model (Pedersen, 1994; Sue, 2001; Sue et al., 1992) and curriculum reframing. Teachers of Black, Indigenous, and students of color around the world will find this article particularly useful because there are limited research-based recommendations applicable to schools in the U.S. and around the world.
\end{abstract}

KEYWORDS: COVID-19, culturally responsive teaching, culturally sustaining pedagogy, curriculum reframing, cultural competence

\author{
Cultural Imbalance: White Teachers, Diverse Schools \\ Literature Review \\ Recommendations for Supporting Black, Indigenous, and Students of Color \\ in Learning Contexts Transformed by COVID-19 \\ Conclusion \\ References \\ Author Contact
}

The worldwide COVID-19 pandemic cast a glaring light on the educational inequities present in schools across the United States. From the onset of the crisis, the effects of institutional racism in school systems across the country bubbled to the surface amidst the widening chasm in academic access between students of color and their white counterparts. Although most U.S. students were confronted with unexpected new realities brought on by the abrupt switch to remote instruction during the global pandemic in the Spring of 2020, students of color experienced compounding levels of loss. For students from families whose incomes fell near or below the national poverty line, access to technology became an immediate concern. The wrap around services such as food support, health, and counseling services typically provided by school districts for these students were suddenly unavailable. Students whose families were more likely to be employed as essential 
workers meeting the daily needs of Americans sheltering in place at home were precipitously unable to meet their own families.

At the same time, racial and social division among U.S. citizens reached a fever pitch as decades of unresolved tensions erupted following the murders of George Floyd and Breonna Taylor. Stories of Black Americans being harassed, assaulted, and even arrested for participating in everyday acts of life such as running, shopping, and birdwatching flooded social media outlets. Asian American citizens faced an onslaught of hate crimes egged on by politicians and other public officials who blamed China for the world's ills (NBC News, 2020). Americans struggled to make sense of the chaos developing inside its borders. We watched in awe as our façade of leadership in the global fight for justice crumbled. The world watched. Our students watched. And, all the while, teachers were left to mend the wounds of institutional racism left open and festering by these dueling crises.

\section{Cultural Imbalance: White Teachers, Diverse Schools}

As the demographic make-up of public schools in America abounds with racial, ethnic, linguistic, and religious diversity (Dilworth \& Coleman, 2014), White, middle-class females comprise the majority (82\%) of the PK-12 teaching force (U.S. Department of Education, 2016). This cultural mismatch between teachers and students has been met with calls from educational scholars for culturally relevant (Ladson-Billings, 1995, 2004), responsive (Gay, 2002, 2010), and sustaining (Paris, 2012; Paris \& Alim, 2014) teaching practices. More recently the emphasis on systemic educational injustice has given rise to calls for institutional and curricular (Muhammad, 2020) change based on antiracist (Kendi, 2019), abolitionist (Love, 2019), policies and practices that reject white supremacist educational ideology. Teachers are being called to quell the rising storms of systemic injustice made evident by COVID-19. Now, more than ever, school systems are uniquely positioned to create sustained models of equity within schools whose student populations reflect society at large. It is within these spaces, that teachers have the opportunity to join the push toward educational equity for all.

In this article, we offer recommendations for practices that highlight culturally relevant, responsive, and sustaining pedagogy; promote cultural competence among teachers and students; and forefront curriculum reframing to advance the academic success of students of color and push towards greater instructional equity. Specifically, we include suggestions designed to mitigate the impact of COVID-19 on the academic outcomes of students of color. These recommendations prioritize equitable access for all and seek to confront policies shaped by structural racism.

\section{Literature Review}

The recommendations featured in this article are grounded within three bodies of educational research: (a) culturally relevant, responsive, and sustaining pedagogies; (b) cultural competence; and (c) curriculum reframing. We provide historical perspectives on the educational platforms mentioned below and we 
situate them within the context of modern-day schools rebounding from the impacts of COVID-19.

\section{Culturally Relevant, Responsive, and Sustaining Pedagogies}

In her seminal study on teachers of successful African American students, educational pioneer Gloria Ladson Billings (1995) unveiled an instructional framework that would become a road map for culturally conscious educators for years to come. Since that ground-breaking study, culturally relevant pedagogy (CRP) has emerged as a bedrock upon which educators seek to strengthen their work with African American students by promoting high academic achievement, building cultural competence, and working to develop students' sociopolitical consciousness. Ladson-Billings defines academic achievement as the intellectual development that occurs based on the instruction and experiences that students encounter in the classroom.

CRP is grounded in the belief that cultural competence occurs when students are taught to acknowledge and celebrate their own culture, while learning to appreciate and understand the cultures of others. As such, proponents of CRP recognize that sociopolitical consciousness expands learning beyond the classroom walls as students are encouraged to identify and solve real world problems through social action. For teachers navigating the world during the global pandemic, being culturally relevant requires direct action in support of our most vulnerable student populations. Culturally relevant teachers seek ways to support students who are negatively impacted by inequitable policies and practices.

Just as CRP set the stage for transformational work with students of color, Culturally Responsive Pedagogy brought forth fundamental characteristics of and expectations for teachers charged with educating students of color. Gay (2002, 2010) defined culturally responsive teaching as the intentional use of students' background knowledge, cultural experiences, frames of reference, and learning styles to make instruction more meaningful and relevant for them. Gay $(2002,2010)$ led the call to equip teachers with culturally responsive knowledge, attitudes, and skills during preservice teacher education programs as a means of enhancing the opportunities for school success among students of color. Gay touted the benefits of proper training for teachers and believed that teachers should design instructional practices to match the learning styles of the students in their care. Specifically, Gay placed responsibility on schools for establishing continuity between the ways that students of color learn and communicate, and the instructional approaches to teaching and learning used by educators within the school (2010). Given the widespread impact of COVID-19 on students of color in the United States, schools must work to counteract the practices that disadvantage students whose knowledge, language, and communication styles differ from those of the dominant culture.

In 2012, Django Paris offered the term Culturally Sustaining Pedagogy (CSP) as an alternative resource pedagogy designed to support the present and future value of our expansive multiethnic, multilingual society. CSP "lovingly critiques" culturally relevant and responsive pedagogies, and questions whether 
the research and practices that have been done under the umbrella of culturally relevant and responsive pedagogies are enough to "ensure maintenance of the languages and cultures of African American, Latino/a, Indigenous American, Asian American, Pacific Islander American, and other longstanding and newcomer communities in our classroom" (Paris, 2012, p. 94). According to Paris, CSP moves beyond relevance or responsiveness to students' culture and "seeks to perpetuate and foster-to sustain-linguistic, literate, and cultural pluralism as part of the democratic project of schooling" (Paris, 2012, p. 94). CSP can be distinguished from CRP by its critical stance toward and critical action against inequitable educational practices. Moreover, CSP "support[s] young people in sustaining the cultural and linguistic competence of their communities while simultaneously offering access to dominant cultural competence" (Paris, 2012, p. 94). Accomplishing this goal during COVID-19 may require nuanced relationships and connections between teachers and valued members and leaders within the communities served by schools. Partnerships that work to sustain the cultures, values, and priorities of a community show promise in attaining equal access for all.

\section{Cultural Competence}

According to the National Education Association (NEA, 2020), cultural competence involves "having an awareness of one's own cultural identity and views about difference, and the ability to learn and build on the varying cultural and community norms of students and their families" (cultural competence section). Culturally competent educators establish their own cultural identity, demonstrate understanding and respect of other cultures, and evolve in that understanding as they interact with students and families from cultural groups that differ from their own (Cross, 2003; Miller \& Mikulec, 2014). Culturally competent educators also "understand the within-group differences that make each student unique, while celebrating the between-group variations that make our country a tapestry" (NEA, 2020).

Teachers committed to the journey toward cultural competence recognize their own biases, are familiar with their students' personal and cultural backgrounds, and strive to construct welcoming learning communities where students' values and cultures are respected (Johnson, 2015; Weinstein et al., 2004). These characteristics are especially important for teachers attempting to manage the fallout from the COVID-19 pandemic that led to misinformation, hate crimes, and harassment against Asian-Americans in the U.S. amidst the simultaneous episodes of racism, discrimination, and murder of unarmed African Americans by the police. For example, according to NBC News (2020), over $30 \%$ of Americans reported that they witnessed someone blaming Asians for the pandemic and $60 \%$ of Asian Americans reported that they encountered this hatred. The pandemic inflamed racism against Asians and increased global concerns regarding hate crimes and bullying against Asian American students.

For decades, scholars have explored the impact of varying models of cultural competence (Mason, et al., 1996; Pedersen, 1994, Sue, 2001). Mason et al (1996) designed a model focused on respect, self-assessment, and 
attentiveness to difference, while a majority of research within the area of cultural competence (e.g., Hall \& Theriot, 2016; Iverson, 2012; Lehman, 2017; Vincent \& Torres, 2015) favored a framework based on attitudes/beliefs, knowledge, and skills. Within the framework, multicultural competence is systematically developed from cultural awareness to cultural knowledge toward cultural skills and ability (Sue et al., 1998). The awareness domain involves recognizing one's own biases as well as the sociopolitical issues that affect students from varying backgrounds. The knowledge domain involves acquiring objective information about cultural diversity (e.g., learning directly from people within communities that are culturally different from one's own). Finally, the skills domain involves integrating one's newly acquired knowledge and awareness to positively impact groups.

Similarly, the cultural competence model by Sue and his colleagues (Sue et al., 1992; Sue, 2001) suggest the domains of competence. The model addresses (a) understanding students' own biases, perspectives, and beliefs; (b) acquiring knowledge of diverse views and multicultural perspectives; and (c) developing skills on how to appropriately interact and communicate with people from all backgrounds. The three competence components are: belief/attitude, knowledge, and skill. Both of these cultural competence approaches are relevant and valid and, together, provide the conceptual base for recommendations included in this article.

\section{Reframing Curriculum}

As evidenced above, the quest to secure an equitable education for Black, Indigenous, and students of color requires both an in-depth, comprehensive evaluation of the pedagogical practices of teachers, as well as an unbiased assessment of the impact of those practices on the academic outcomes of students. Educational systems seeking to maximize student potential and make learning accessible to all must devote equal attention to the content, values, beliefs, perspectives, omissions, and inclusions presented within the curriculum itself. Regular evaluation and reframing of the curriculum must be prioritized in spaces where students of color are regarded as essential and equitable educational outcomes become a matter of practice. Curriculum reframing shifts the focus from how instruction is presented to what and who is included as part of daily instruction. As students engage in the learning process, the lack of diverse perspectives within the curriculum poses an ancillary threat to the identity development and sense of self for those students whose ways of doing and being are not aligned with those of the dominant culture. Students are more likely to sustain deeper levels of engagement and attain higher level of achievement when the curriculum is inclusive of their experiences and identities (Thomas, 2016).

The process of curriculum reframing involves a general screening of the books, materials, and resources adopted by schools and districts for cultural, ethnic, gender, and ability inclusion. Existing units and lessons are evaluated to assess the representation, validation, and affirmation of Black, Indigenous, and people of color whose cultural norms vary from those of the dominant culture. Stereotypes, biased portrayals, and implied deficiencies of historically marginalized or oppressed groups are targeted and removed from the curriculum. 


\section{Recommendations for Supporting Black, Indigenous, and Students of Color in Learning Contexts Transformed by COVID-19}

\section{Employ Culturally Responsive and Sustaining Practices}

As students and families adjust to new ways of being in a world transformed by COVID-19, schools must also find ways to accommodate the communities they serve. This may look different according to the needs of the communities and the resources that are available. When its schools were forced to close in March of 2020, the South Bend Community School corporation in South Bend, Indiana provided school buses with broadband Internet access to assist students in need of Internet access in completing their school assignments at home (Hannon, 2020). The school system installed Wi-Fi routers on its buses and sent the buses to 40 different locations across the areas they serve including parks and apartment complexes. The locations were selected based on feedback from surveys that helped identify which homes had Internet access and which homes did not. Monday through Thursday from 8:00 am to 4:00 pm, buses were parked in the community and accessible to students who had limited access to Wi-Fi. Over time, the school district began pairing meal service with the Wi-Fi service via the school buses. Eventually, students were able to retrieve breakfast, lunch, and dinner from the same school buses where they accessed Wi-Fi services to complete their school assignments. This addition was significant because it targeted students and families living in food deserts who qualified for free or reduced lunch (Hannon, 2020).

Similarly, the Austin Independent School District sent 100 school buses across the city to provide Wi-Fi and Chromebooks to students in need (Hannon, 2020). One apartment complex in particular hosted 20 school buses staggered 150 feet apart to ensure that the many students residing there were able to take advantage of the service. Two school employees - a bus driver and a bus monitor - remained present on each bus to monitor students and facilitate proper COVID protocol. The buses were available to students Monday through Friday from 8:00 am to 2:00 pm (Hannon, 2020).

Technology can be used in other culturally responsive ways that improve student learning. Vegas and Winthrop (2020) call for the creation of "power-up" schools to transform teaching and learning and harness education technology in response to COVID-19. Specifically, the researchers suggest scaling up quality instruction through strategies such as pre-recorded lessons of high-quality teaching. These recordings could allow students to move at an individual pace as needed and re-watch or review content for clarification and support. The active and engaging lessons featured on the recordings would involve research-based instructional strategies, and thus ensure equitable access to high quality instruction for students from all backgrounds. Additionally, Vegas and Winthrop (2020) recommend facilitating differentiated instruction through methods such as computer adaptive learning or live one-on-one tutoring. This culturally responsive instructional strategy allows educators to adapt instruction to the learning styles, 
preferences, and needs of individual students. Vegas and Winthrop (2020) also recommend expanding opportunities for student practice and increasing student engagement to harness education technology as a means of culturally responsive support for students during COVID-19. Both of these strategies could be met through interactive technology-based resources such as videos, electronic books, manipulatives, and games.

\section{Develop and Support Cultural Competence in Partnership with Students and Families}

COVID-19 elevated the role of families in daily instruction and partnerships with teachers and schools. As such, teachers reported more frequent, meaningful, and visible communication with caregivers since the onset of the pandemic. Teachers, schools, and districts embraced innovative strategies to foster family engagement in the educational process. In one example, the South Dakota Statewide Family Engagement center designed weekly "Conversation Cafes" to help facilitate discussions and build connections between and among caregivers and schools. These virtual share sessions were offered in both English and Spanish and allowed families to share their challenges and successes in dealing with COVID-19. Conversation Cafes present a unique opportunity for teachers striving towards cultural competence to recognize their own biases and reflect on differing ways of doing and being that exist between students, families, and themselves (National Center for Families Learning, 2020). Social media has also played an important role in supporting family engagement within schools. When COVID-19 prompted virtual instruction for students, Dunseuth Elementary School turned to Facebook as a means to maintain contact and share instructional videos. Recognizing that the shift to online instruction presented new and developing challenges for families, teachers were able to engage in guided reflection of their responses to the pandemic as they assisted students and families in making sense of their own experiences through the use of visual communication technology.

Culturally competent teachers can help parents identify appropriate behavioral or instructional strategies for supporting their students. It is no secret that students learn in different ways and have varying levels of tolerance for online learning. Helping families find ways to support their children can lead to higher levels of engagement and achievement for students learning in online environment. Communicating with parents via email, Zoom, or Skype regarding their child's adjustment to online learning can help teachers and caregivers create individualized learning plans based on academic as well as social and emotional needs.

Cultural competence involves awareness and a developing sense of self. Modeling mindfulness skills for students and families can help teachers support their own personal development, as well as provide support for students and caregivers during challenging and stressful times. Practicing self-care and healthy living strategies can ensure that students and families understand the importance of sleep, nutritious diets, and exercise. Teachers seeking to develop their cultural competence recognize the importance of acting as advocates for the whole students. 


\section{Acknowledge the Role of Bias, Prejudice, and Racism}

At the same time that COVID-19 pandemic blanketed parts of the U.S. in March of 2020, long-held beliefs regarding the diminished value of the lives of Black, Indigenous, and people of color resurfaced in the form of racial abuse and assault on people of color. Hate crimes against Asians coupled with the murders and maltreatment of Blacks across the country gave rise to bigotry and racism that could no longer be ignored. Bullying of Asian American students increased, solidifying this group's role as the most frequent victims of bullying among all ethnic groups (Wu et al., 2015).

The reality of racism that had always been evident to some prompted a barrage of public statements disavowing racism and hate. Many of the nation's largest companies and corporations including Walmart, Ford, and Johnson \& Johnson created policies against racism and many hired new employees whose primary role was to examine, identify, and resolve inequities in company policies and practices. For the first time, the climate in America appeared to shift from tolerance to abolishment. Although policy changes are just the beginning of a complex journey towards anti-bias and anti-racist embodiment, taking these steps clearly denotes the direction in which these businesses are seeking to turn.

We recommend that schools and school districts follow suit with many of the CEOs and companies that have actively acknowledged their need to reconsider and revise the policies and practices that lead to unfair treatment of Black, Indigenous, and people of color. In the same way, schools must examine their curricular tools to identify and remove bias depictions and representations that cause harm and mistreatment to those outside of the dominant culture as a result of inadequate or incomplete information on varying subjects. According to Bryan-Gooden and colleagues (2019), curriculum refers to a comprehensive set of learning objectives; units and lessons that outline what teachers teach each day and week; student assignments, activities, and projects; and books, materials, presentations, videos, and readings. A textbook and teacher's manual purchased from a publisher, a notebook of lesson plans compiled from different sources, or a reading list with a packet of corresponding activities developed by teachers are all examples of curriculum (Bryan-Gooden et al., 2019).

The NYU Metro Center offers a culturally responsive scorecard for both English language arts and STEAM (science, technology, engineering, arts, and math) areas to support schools in mining the content within their curriculum as they attempt to center students' cultures, identities, and contexts (Bryan-Gooden et al., 2019). The scorecards are divided into three sections: representation, social justice, and materials. As part of the representation section of the scorecard, users of the tool are invited to consider the diversity and portrayal of characters, as well as the authors of the texts that students are required to read. In the area of social justice, schools and school systems using the scorecard unpack decolonization, power, and privilege within the curriculum. In this area, the scorecard emphasized centering multiple perspectives and connecting learning to real life action. Finally, the scorecard encourages reflection on the strategies and approaches included within the teacher's materials. 
Similarly, the Virginia Department of Education (VDOE) offers a curriculum reframing checklist to help guide schools in regularly examining their curriculum for bias. According to VDOE, curriculum reframing "mitigates bias and ensures that diverse groups from all rings of culture are represented, validated, and affirmed" (2020, p. 35). The checklist includes a series of questions that guide schools in yearly audits of the curriculum. The audits screen for items such as historical accuracy, inclusion of people with disabilities, and the exclusion of stereotypes and perceived deficiencies of historically marginalized or oppressed groups. The checklist also accounts for biased portrayals of the dominant culture. One item on the checklist reads "problems faced by historically marginalized/oppressed cultures are not resolved through the benevolent intervention of the dominant culture" (VDOE, 2020, p. 36).

\section{Conclusion}

The devastating impacts of COVID-19 on the educational outcomes of Black, Indigenous, and students of color are wide and far reaching. There may yet be undiscovered educational effects that impact students' social, emotional, and academic progress for years to come. As educators seek to support students of color during this time of pain, loss, isolation, and instability, care must be taken to counteract the forces that work to sustain educational inequities. We believe in culturally relevant, responsive, and sustaining educational practices that promote cultural competence and reframe curriculum to accurately reflect the roles and contributions of traditionally marginalized and oppressed populations. We support attempts to partner with students and families to acknowledge and remove racism and bias from the curriculum. We recommend a sustained focus on culturally sound practices that reject bias and racism, and an active attempt to harness the potential for equitable education brought to light by the worldwide pandemic known as COVID-19.

\section{References}

Bryan-Gooden, J., Hester, M., \& Peoples, L.Q. (2019). Culturally responsive curriculum scorecard. Metropolitan Center for Research on Equity and the Transformation of Schools, New York University.

Cross, B. (2003). Learning or unlearning racism: Transferring teacher education curriculum to classroom practices. Theory into Practice, 42, 203-209. https://doi.org/10.1207/s15430421tip4203_6

Dilworth, M. E., \& Coleman, M. J. (2014). Time for a change: Diversity in teaching revisited. National Education Association.

Gay, G. (2002). Culturally responsive teaching in special education for ethnically diverse students: Setting the stage. International Journal of Qualitative Studies in Education, 15, 613-629. https://doi.org/ 10.1080/0951839022000014349

Gay, G. (2010). Culturally responsive teaching: Theory, research, and practice (2nd ed.). Teacher College Press. 
Hall, J. C., \& Theriot, M. T. (2016). Developing multicultural awareness, knowledge, and skills: Diversity training makes a difference? Multicultural Perspectives, 18(1), 35-41. https:// 10.1080/15210960.2016.1125742

Hannon, T. (2020, April 8). School bus wi-fi hotspots aide student learning during COVID-closures. School Transportation News. Retrieved April 25, 2021 from: https://stnonline.com/special-reports/school-bus-wi-fi-hotspots-aidestudent-learning-during-covid-19-closures/

Iverson, S. V. (2012). Multicultural competence for doing social justice: Expanding our awareness, knowledge, and skills. Journal of Critical Thought and Praxis, 1(1), 62-87. https://doi.org/10.31274/jctp-180810-14

Johnson, N. I. (2015). The culturally responsive classroom without borders. Independent School, 74(4), 80-84.

Kendi, I. X. (2019). How to be an antiracist. One World.

Ladson-Billings, G. (1995). But that's just good teaching! The case for culturally relevant pedagogy. Theory into Practice, 34(3), 159-165. https://doi.org/10.1080/00405849509543675

Ladson-Billings, G. (2004). New directions in multicultural education: complexities, boundaries, and critical race theory. In J. Banks \& C. McGee Banks (Eds.), Handbook of Research on Multicultural Education (2 ed., pp. 50-65). Jossey-Bass/A Wiley Company.

Lehman, C. L. (2017). Multicultural competence: A literature review supporting focused training for preservice teachers teaching diverse students. Journal of Education and Practice, 8(10), 109-116.

Love, B. L. (2019). We want to do more than survive: Abolitionist teaching and the pursuit of educational freedom. Beacon Press.

Mason, J. L., Benjamin, M. P., \& Lewis, S. A. (1996). The cultural competence model: Implications for child and family mental health services. In C. A. Heflinger \& C. T. Nixon (Eds.), Families and the mental health system for children and adolescents: Policy, services, and research. Children's mental health services (pp. 165-190). SAGE Publications.

Miller, P. C., \& Mikulec, E. A. (2014). Pre-service teachers confronting issues of diversity through a radical field experience. Multicultural Education, 21(2), 18-24.

Muhammad, G. (2020). Cultivating genius: An equity framework for culturally and historically responsive literacy. Scholastic Incorporated.

National Center for Families Learning (2020). Successful family engagement during COVID-19. Retrieved April 25, 2021 from https://www.familieslearning.org/pages/successful-family-engagementcovid-19 
National Education Association (2020). Cultural Competence. Retrieved April 25, 2021 from https://www.nea.org/professional-excellence/professionallearning/resources/cultural-competence

NBC News (2020, April 28). Over 30 percent of Americans have witnessed COVID19 bias against Asians. Retrieved April 25, 2021 from https://www.nbcnews.com/news/asian-america/over-30-americans-havewitnessed-covid-19-bias-against-asians-n1193901

Paris, D. (2012). Culturally sustaining pedagogy: A needed change in stance, terminology, and practice. Educational Researcher, 41(3), 93-97. https://doi.org/10.3102/0013189X12441244

Paris, D., Alim, H. S. (2014). What are we seeking to sustain through culturally sustaining pedagogy? A loving critique forward. Harvard Educational Review, 84, 85-100. https://doi.org/10.17763/haer.84.1.982/873k2ht16m77

Pedersen, P. (1994). A handbook for developing multicultural awareness. (2nd ed.). American Counseling Association.

Sue, D. W, Carter, R. T, Casas, J. M., Fouad, N. A., Ivey, A. E., Jensen, M., LaFromboise, T, Manese, J. E., Ponterotto, J. G., \& Vasquez-Nutall, E. (1998). Multicultural counseling competencies: Individual and Organizational Development. Multicultural aspects on counseling series 11. SAGE Publications.

Sue, D. W. (2001). Multidimensional facets of cultural competence. The Counseling Psychologist, 29(6), 790-821. https://doi.org/10.1177/0011000001296002

Sue, D. W., Arredondo, P., \& McDavis, R. J. (1992). Multicultural competencies/ standards: A pressing need. Journal of Counseling \& Development, 70, 477-486. https://doi.org/10.1002/j.1556-6676.1992.tb01642.x

Thomas, $L$ (2016). Developing inclusive learning to improve the engagement, belonging, retention, and success of students from diverse groups. In: M. Shah, A. Bennett, E. Southgate (Eds.), Widening higher education participation. A global perspective (pp.135-159). Oxford: Elsevier.

U.S. Department of Education, Office of Planning, Evaluation and Policy Development, Policy and Program Studies Service (2016). The state of racial diversity in the educator workforce. Retrieved April 26, 2021 from: https://www2.ed.gov/rschstat/eval/highered/racial-diversity/state-racialdiversity-workforce.pdf

Vegas, E., \& Winthrop, R. (2020, September 8). Beyond reopening schools: How education can emerge stronger than before COVID-19. Brookings Institution. Retrieved April 25, 2021 from online: https://www.brookings.edu/research/beyond-reopening-schools-howeducation-can-emerge-stronger-than-before-covid-19/ 
Vincent, S. K., \& Torres, R. M. (2015). Multicultural competence: A case study of teachers and their student perceptions. Journal of Agricultural Education, 56(2), 64-75. https://10.5032/jae.2015.02064

Virginia Department of Education (2020). Navigating EdEquityVA: Virginia's road map to equity. Retrieved April 26, 2021 from: www.doe.virginia.gov/edequityva/navigating-equity-book.pdf

Weinstein, C. S., Tomlinson-Clarke, S., \& Curran, M. (2004). Toward a conception of culturally responsive classroom management. Journal of Teacher Education, 55(1), 25-38. https://doi.org/10.1177/0022487103259812

Wu, I. H. C., Lyons, B., \& Leong, F. T. L. (2015). How racial/ethnic bullying affects rejection sensitivity: The role of social dominance orientation. Cultural Diversity and Ethnic Minority Psychology, 21(1), 156-161. https://10.1037/a0037930

\section{Author Contact}

Min Mize mizem@winthrop.edu

Department of Education Core, 106 Withers Building, Rock Hill, SC 29733

Crystal Glover gloverc@winthrop.edu

Department of Curriculum and Pedagogy, 106 Withers Building, Rock Hill, SC 29733 